\title{
ORIENTATION OF TRANS-SAHARAN PASSERINE MIGRANTS IN SOUTHWESTERN SPAIN - REVISITED
}

\author{
Przemysław Busse
}

\begin{abstract}
Busse P. 2019. Orientation of Trans-Saharan passerine migrants in Southwestern Spain revisited. Ring 41: 3-15.

At the end of the 1980s, a relatively large data set was collected from orientation cage tests of nocturnal migrants caught in one locality in south-western Spain. It was published in The Auk in 1989. At the time of publication, the use of orientation cages was a major advance in detailed studies on passerine migration patterns. The basic evaluation procedure was to calculate the average vector of all numbers representing bird activity in a number of sectors of the full wind-rose and to use the Rayleigh test to determine the statistical significance of the distribution. However, due to hidden assumptions in the procedure used at that time, the resulting heading patterns could be called into question in light of further methodological development. The paper revisits the original set of orientation data collected in the last century in the reported study. The new results from the multimodal distribution accepting procedure are compared with the older pictures and are found to be much better at explaining the migration pattern there. In particular, the Garden Warbler and Reed Warbler, which were claimed to be 'disoriented', now show acceptable directionality patterns which do not differ in shape from those of other species.
\end{abstract}

P. Busse, Bird Migration Research Foundation, Przebendowo 3, 84-210 Choczewo, Poland; e-mail: busse@wbwp-fund.eu

Keywords: orientation cage data, methods, heading pattern, passerines, southern Spain

\section{INTRODUCTION}

At the end of the 1980s, a relatively large data set was collected and published from orientation cage tests of nocturnal migrants caught in one locality in south-western Spain (Hilgerloh 1989b). The rationale for the work, presented at the beginning of the text, is convincing: 'Radar observations in the southwestern Iberian Peninsula revealed south-southwesterly directions for trans-Saharan passerine migrants (Hilgerloh 1985, 1988, 1989a). If an individual species was oriented to the southeast (Zink 1977, Gwinner and Wiltschko 1978), one would not realize it on the radar screen. Orientation tests are necessary to determine the orientation direction of different species. 
The questions arise, whether mean directions of species differ significantly from one another and whether they correspond to the mean directions observed by radar.' The rationale still holds, although the research methods for solving these problems have greatly evolved since that time.

Since the end of the 20th century the radar technique and evaluation of results have developed substantially, but it is still not possible to use radar to follow the migration patterns of individual species of small passerines, in terms of either numbers or direction. Thus, orientation cage tests are the only method for following the passage pattern of small passerine species. New techniques based on loggers and satellite transmitters are still of very limited use in population studies of these species.

At the time of publication of Hilgerloh's paper (op. cit.), the use of orientation cages was a major advance in detailed studies on passerine migration patterns. The basic practical assumption for using the orientation cage was that the author was convinced that the behaviour of the bird in the cage shows the actual tendency of the individual to move from the testing location to the distant winter-quarter, which in autumn is located to the south. The only type of orientation cage available for larger studies in field conditions at that time was Emlen's funnel cage (Emlen and Emlen 1966) - see below in the 'Field method' section. A few years later a new orientation cage design was developed (Busse 1995). This was not a funnel shape, but a flat cage, much easier for practical application in field work. This enabled the collection of a huge amount of orientation data in different parts of Europe and the Near East. The compatibility of these two field procedures was confirmed years ago (Nowakowski and Malecka 1999, Zehtindjiev et al. 2003, Ożarowska and Yosef 2004) and finally discussed in detail by Busse (2017).

In the 1980s the first statistical method for evaluation of circular data (such as orientation cage data) was developed (Batschelet 1981). The basic procedure was to calculate the average vector of all numbers representing the bird's activity in a number of sectors of the full wind-rose and to use the Rayleigh test to determine the 'statistical significance' of the distribution. This procedure was enthusiastically applied to the evaluation of that kind of data. Unfortunately, owing to this enthusiasm and the lack of alternative procedures, Batschelet's procedure was regarded the 'standard' or 'classic' method. However, there were hidden assumptions: (1) at the individual level, that the bird shows exactly one direction to the winter-quarter (other traces of the bird's behaviour are due to 'disorientation'); (2) at the group (population) level - all birds from the studied group show exactly one direction (goal of orientation). According to these assumptions any individual directions calculated other than the 'proper' ones were treated as the result of 'disorientation' or simply as natural variation in the group. This procedure was used in the paper we are revisiting.

The introduction of a new orientation cage design was associated with a rethinking of the foundation of the data evaluation process. Even the first publication presenting the new cage design (Busse 1995) claimed that real directional distributions originating in orientation cage tests are frequently multimodal, both at the level of individual tests and in analysis of group distributions. This was later confirmed in a number of publications (e.g. Busse and Trocińska 1999, Trocińska 2001, Ożarowska and Yosef 2004, Muś 2005, 2008, Ożarowska et al. 2013) and can now be considered 
common knowledge. This means that the traditional, 'standard' procedure is fundamentally invalid for most test data, because Batschelet's calculation is only valid for unimodal distribution of the data. Hence the data must be treated differently, in such a way that multimodal distributions can be taken into consideration. Pyle (2002) praised the field technique of the new procedures, and Newton (2008) expressed appreciation for the multimodal model of orientation data. Then two evaluation procedures were proposed, an estimation procedure and a calculation procedure. The estimation procedure has been used for many years in work on vast material collected using Busse's flat cage (e.g. Nowakowski and Malecka 1999, Busse et al. 2001, Trocińska et al. 2001, Formella and Busse 2002, Zehtindjiev et al. 2003, Ożarowska et al. 2004, Ożarowska and Yosef 2004, Ściborska and Busse 2004, Adamska and Filar 2005, Adamska and Rosińska 2006, Rosińska and Adamska 2007, Stępniewska et al. 2011, Stępniewski et al. 2011) and the 'calculation procedure' was proposed by Ożarowska et al. (2013) after a few preliminary reports developing Bayesian modelling (Muś 2005, 2008, Ożarowska and Muś 2008). The calculation procedure has been well documented using Bayesian statistics (see Ożarowska et al. 2013 for details). Both procedures are compared in detail in a paper by Busse (2018).

The old set of data being revisited was collected in a very interesting locality, a key point of the Atlantic flyway in southern Spain. The revisiting provides an opportunity to compare results obtained using one field procedure, but two competing methods of evaluation of this kind of data.

\section{METHODS OF ANALYSES}

\section{Collecting the data in the field (after Hilgerloh 1989b)}

"Test birds were captured in the "Algaida" pine forest near Sanlucar de Barrameda $\left(36^{\circ} 48^{\prime} \mathrm{N}, 06^{\circ} 17^{\prime} W\right)$ at the mouth of the river Guadalquivir (southwestern Spain) during August, September, and October in 1985 and 1987. I tested the most numerous species (Hilgerloh 1985b) on 52 nights. These included Pied Flycatcher (Ficedula hypoleuca), European Willow Warbler (Phylloscopus trochilus), Garden Warbler (Sylvia borin), European Nightingale (Luscinia megarhynchos), Greater Whitethroat (Sylvia communis), Spotted Flycatcher (Muscicapa striata), and European Reed-Warbler (Acrocephalus scirpaceus). Sample sizes varied according to the number of birds captured. I tested each bird on the night after the day on which it was captured; subsequently, I released it. Orientation tests were performed outdoors at the location of capture. I used funnelshaped orientation cages (Emlen and Emlen 1966) to record the birds' activity; typewriter correction paper was the recording medium (Beck and Wiltschko 1981). Test commenced shortly after sunset and lasted $90 \mathrm{~min}$. The tests were performed on moonless nights with less than 3/8 overcast and with a natural magnetic field.' The data were recorded, quantifying footprint densities in each of twenty-four $15^{\circ}$ sectors. 


\section{Original evaluation of the data (after Hilgerloh 1989b)}

Using the sector data values 'Nightly mean directions relative to true north were calculated by vector analysis (Batschelet 1981) and pooled for analysis of individual species. Birds with scratches total activity were excluded. A mean direction of orientation were calculated for each species with 15 tested individuals. The Rayleigh test was used to test for non-uniformity of the distributions for comparisons between groups, I used the Mann-Whitney U-Test and the Watson-Williams Test.' The style of the graphic presentation of both levels of analysis (individual and group) is illustrated in Figure 1 (see below).
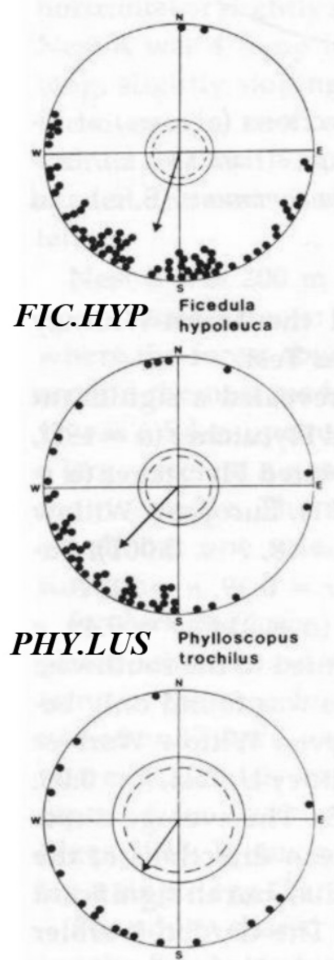

SYL.COM sylvia communis

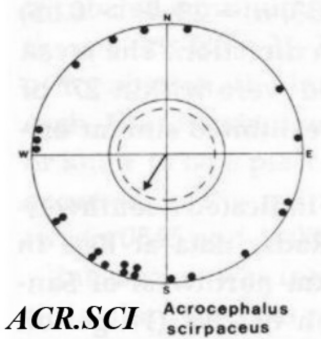

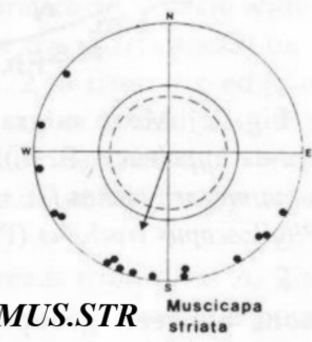

MUS.STRato

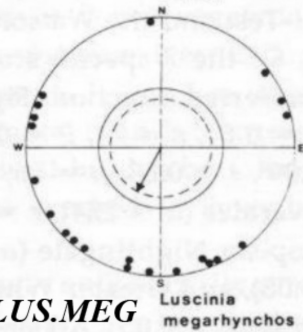

LUS.MEG $\begin{gathered}\text { Luscinia } \\ \text { megarhynchos }\end{gathered}$

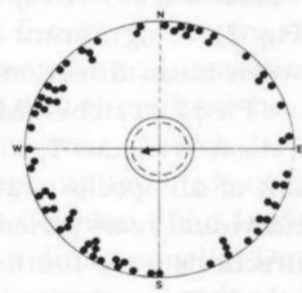

SYL.BOR Sylvia borin

Fig. 1. Orientation of long-distance passerine migrants. Each dot represents one night's average for an individual. The arrow represents the mean vector; the two inner circles are the 5\% (dotted) and the 1\% significance border for the length of the mean vector (Rayleigh Test). After Hilgerloh (1989b). 


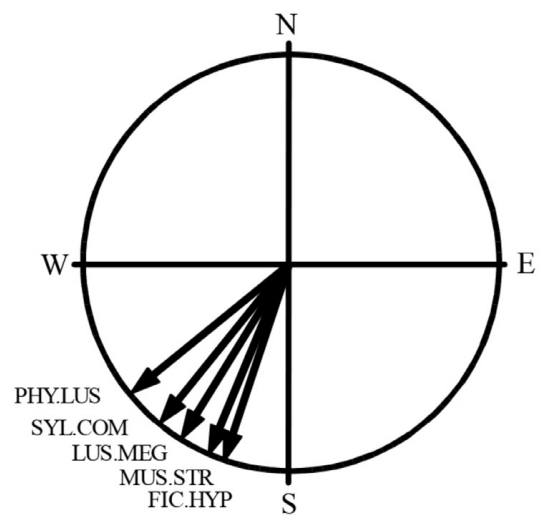

Fig. 2. Mean migration directions (arrows) of species (for species codes see Table 1) shown in Fig. 2 in the revisited paper (Hilgerloh 1989b); slightly modified.

\section{Evaluation of the data by the estimation procedure}

Like the original evaluation procedure used by Hilgerloh (1989b), the evaluation procedure here involved two-step basic processing (Busse 2018): (1) the set of data for the tested individual was processed using ORIENT 4.6 software, checking the data distribution $\left(c h i^{2}\right)$, estimating modality, and defining the resulting vectors (16-sector direction and 'power' as a percentage of the whole distribution); (2) the group distribution pattern, which is a sum of individual vectors, was presented as the total distribution on radar graphs created in available spreadsheet software (here QuattroPro Ver. 8), after which the estimated dominating directions were set up. Unlike the 'classic' method, where only one resulting direction is presented, multimodal patterns are allowed here (see Table 1 for the individual bird test level; for the group level, compare Fig. 3). Moreover, the axes obtained are interpreted as arrival and departure directions. A more detailed discussion of the methodology is available in the paper by Busse (2018) (the arrival-departure interpretation in the section 'Reversed headings...').

Table 1

Numbers of modes found within the distribution of original data in 8 sectors. FIC.HYP Ficedula hypoleuca, Pied Flycatcher, MUS.STR - Muscicapa striata, Spotted Flycatcher, PHY.LUS - Phylloscopus trochilus, Willow Warbler, LUS.MEG - Luscinia megarhynchos,

Nightingale, SYL.COM - Sylvia communis, Whitethroat, SYL.BOR - Sylvia borin, Garden Warbler, ACR.SCI - Acrocephalus scirpaceus, Reed Warbler

\begin{tabular}{|c|c|c|c|c|c|c|c|c|c|}
\hline $\begin{array}{c}\text { Number } \\
\text { of modes }\end{array}$ & FIC.HYP & MUS.STR & PHY.LUS & LUS.MEG & SYL.COM & SYL.BOR & ACR.SCI & Total & $\%$ \\
\hline $\mathbf{0}$ & 1 & 1 & 11 & 0 & 0 & 0 & 0 & $\mathbf{1 3}$ & 5.0 \\
\hline $\mathbf{1}$ & 33 & 14 & 24 & 11 & 8 & 43 & 12 & $\mathbf{1 4 5}$ & 55.3 \\
\hline $\mathbf{2}$ & 25 & 0 & 10 & 5 & 6 & 19 & 6 & $\mathbf{7 1}$ & 27.1 \\
\hline $\mathbf{3}$ & 11 & 0 & 4 & 3 & 3 & 7 & 3 & $\mathbf{3 1}$ & 11.8 \\
\hline $\mathbf{4}$ & 1 & 0 & 0 & 0 & 1 & 0 & 0 & $\mathbf{2}$ & 0.8 \\
\hline Total & $\mathbf{7 1}$ & $\mathbf{1 5}$ & $\mathbf{4 9}$ & $\mathbf{1 9}$ & $\mathbf{1 8}$ & $\mathbf{6 9}$ & $\mathbf{2 1}$ & $\mathbf{2 6 2}$ & \\
\hline
\end{tabular}



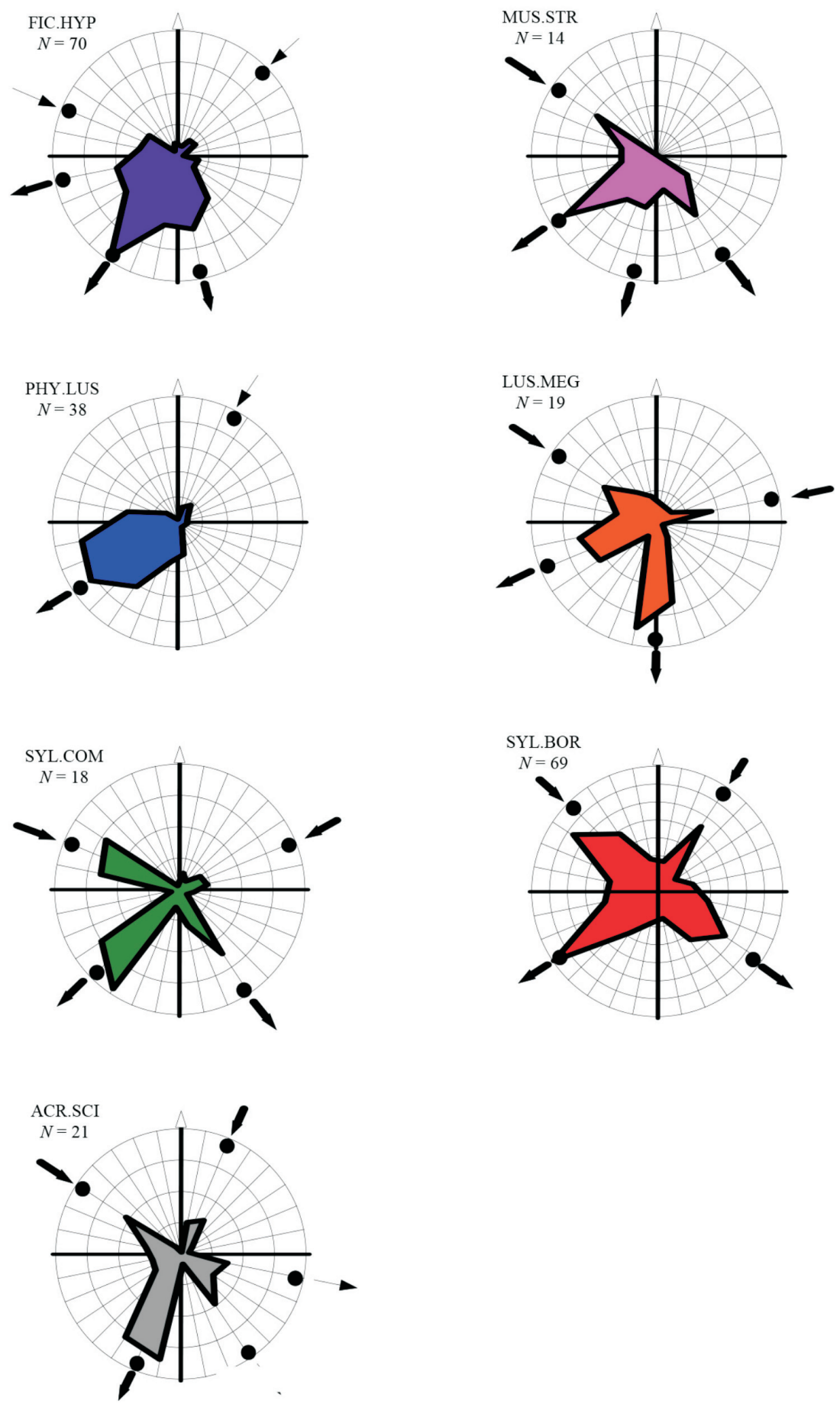

Fig. 3. Heading patterns according to the new evaluation procedure. Dots show the location of the distribution modes, and arrows indicate arrival/departure headings. Species codes as in Table 1. Distribution of species panels as in Figure 1. 


\section{RESULTS AND DISCUSSION}

\section{Original results (after Hilgerloh 1989b)}

'Of the 7 species studied, 5 revealed a significant preferred direction (Fig. 1): Pied Flycatcher $\left(\alpha=197^{\circ}, r=0.64, n=71, P<0.001\right)$, Spotted Flycatcher $\left(\alpha=199^{\circ}, r=0.63\right.$, $n=16, P<0.001)$, European Willow Warbler $\left(\alpha=224^{\circ}, r=0.64, n=48, P<0.001\right)$, European Nightingale $\left(\alpha=208^{\circ}, r=0.39, n=21, P<0.05\right)$, and Greater Whitethroat ( $\left.\alpha=214^{\circ}, r=0.49, n=18, P<0.05\right)$. All species oriented to the southwest (Fig. 2). A significant difference was found only between mean direction of European Willow Warbler and Pied Flycatcher (Mann-Whitney U-Test, $P<0.05$; Watson-Williams Test, $P<0.05)$. The average direction of all species was 208... The Garden Warbler $\left(\alpha=260^{\circ}\right.$, $r=0.15, n=70, P<0.05)$ and European Reed Warbler $\left(\alpha=212^{\circ}, r=0.33, n=23, P<0.05\right)$ did not show a significant mean direction. The mean directions of the species studied were within $27^{\circ}$ of one another. Thus the species exhibited similar orientation direction.'

\section{Results according to the new analytical methodology}

The original data were collected using Emlen's funnel cage as described originally in the revisited paper (Hilgerloh 1989b), where scratches on the correction paper were counted in 24 sectors. These numbers were recalculated for the 8 sectors normally used in the estimation procedure. This was done simply by summing the values of three consecutive 24 -sector values to obtain one 8 -sector value.

Comparison of distributions of arrival and departure headings (Fig. 4) reveals that the general migration pattern of the species is substantially varied. There is a very narrow corridor from the NW running along the southwest coast of Spain which is used for arrival by some individuals of all species (Fig. 5) and a broader arrival stream from the mainland of Spain: Reed Warbler, Willow Warbler and Garden Warbler arrive from the NNE, Whitethroat and Nightingale from the ENE (SE coast of Spain?), and Pied Flycatcher from the NE. The departure headings in the SW quarter of the wind-rose cover a very broad fan of directions. Pied Flycatcher and spotted Flycatcher even have two separate modes of headings within this quarter. Six of seven species (all but the Willow Warbler) have headings in the SE quarter which cover sectors S to SE (absent in ESE sectors). The interpretation of results obtained with the new methodology is summarized in Figure 5. At the site of the field studies, the main stream of migrants arrives from mainland Spain and continues migration SW over the sea. However, there is another stream of migrants, probably less numerous, which in this area follows the SW coast of Spain after changing direction somewhere within southern Portugal. This group seems to change direction more to the south and reach Africa mainly around Gibraltar.

According to Busse's (2018) explanation of the arrival-departure problem, the migrants which simply continue their direction of migration at the site of the field studies should show linear behaviour in the orientation cage: the departure heading should be on the same line as the arrival heading. If there is a change in the migration direction in the area (as in the case of southern Spain), the departure heading 

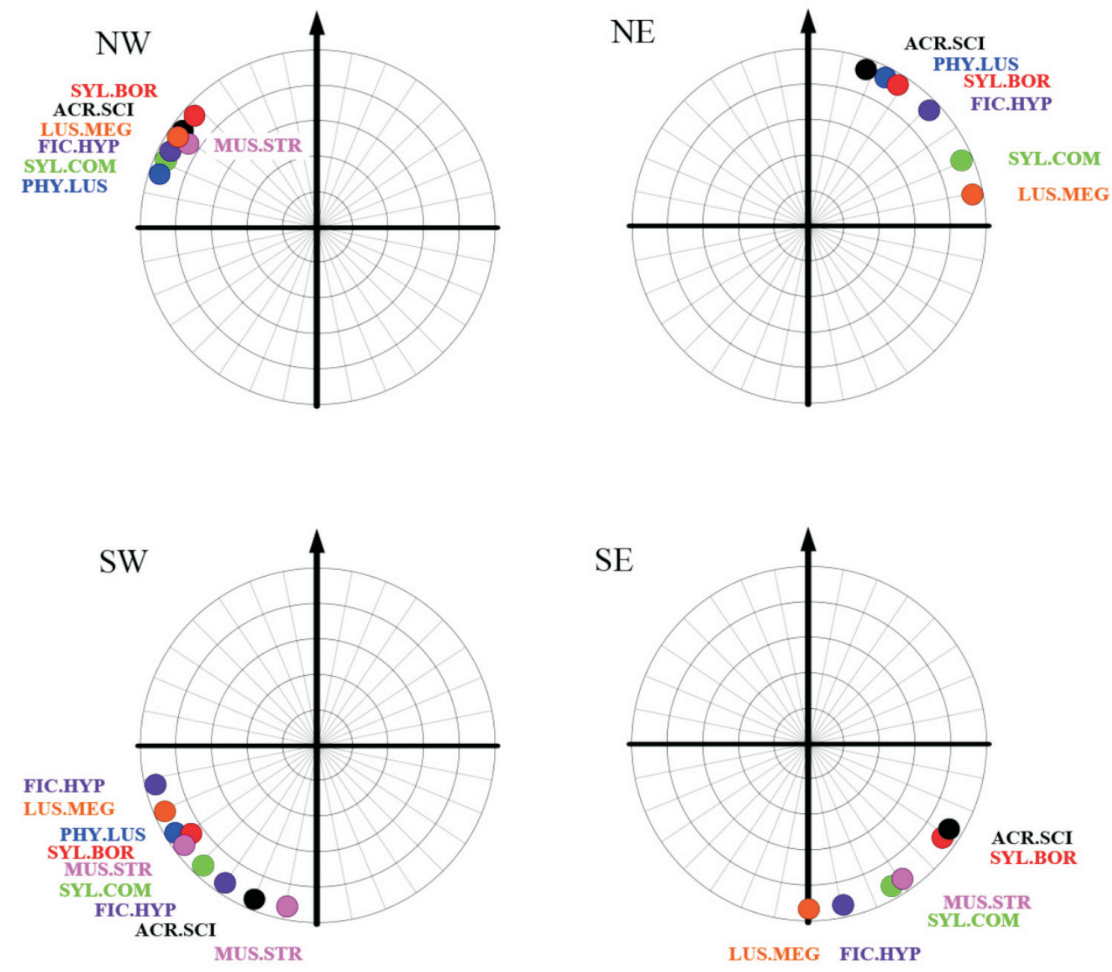

Fig. 4. Distribution of the species' local heading modes by main wind-rose sectors. Species codes as in Table 1 .

should deviate from the line of arrival. Figure 6 illustrates how this looks in Sanlucar. On the NE-SW axis migrants generally move more or less straight ahead. Deviations in individual species deviations are very small $\left( \pm 1^{\circ}-\right.$ Pied Flycatcher and Reed Warbler) or small $\left(-10^{\circ}\right.$ to $\left.+15^{\circ}\right)$. On the other (NW-SE) axis, deviations from the straight line are all directed westward and are mostly very pronounced (from $34^{\circ}$ to $50^{\circ}$ ). Only in Garden Warbler and Reed Warbler are they small $\left(+1^{\circ}\right.$ and $+12^{\circ}$, respectively). It seems that birds arriving from the NW are moving to a more western track, compensating after leaving the correct SW route due to the guiding 'power' of the coast in Portugal.

The general heading pattern of all studied passerines is presented in Figure 7: the main straight forward stream on the NE/SW axis $\left(2^{\circ}\right.$ deviation only) and arrival from the $(\mathrm{W}) \mathrm{NW}$, continuing SE with a correction of $22^{\circ}$.

Relative number distributions of the headings shown in the orientation cage differ between arrival and departure headings (Table 2). Arrival (northern) headings are less common $(21.5-46.4 \%, 32.51 \%$ on average) than departure headings ('correct', southern) - 53.6-78.6\%, on average $66.20 \%$. However, there is a significant difference between the two axes of migration: on the main axis (NE/SW), the share of arrival headings in the cage is low (only 0.27 on average), while on the NW/SE axis it is much higher (1.04 on average). This applies to all species studied, which seems to confirm that there are actually two streams of migrants at this location. 


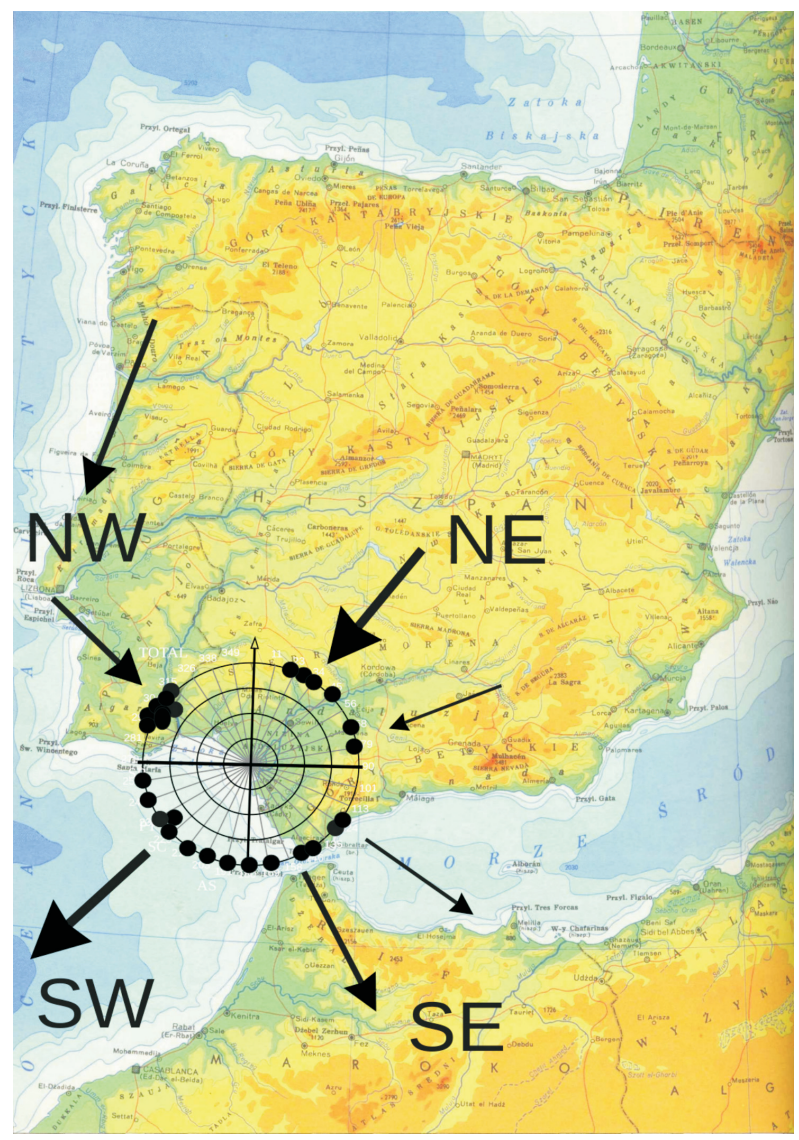

Fig. 5. Spatial interpretation of the migration pattern on the southwestern part of the Iberian Peninsula according to the results of the new analysis of species data

Table 2

Relative frequency patterns of migration by quarters of the wind-rose.

Species codes as for Table 1 .

\begin{tabular}{|c|c|c|c|c|c|c|c|c|c|c|}
\hline \multirow{2}{*}{$n=$} & $\begin{array}{c}\text { FIC. } \\
\text { HYP }\end{array}$ & $\begin{array}{c}\text { MUS. } \\
\text { STR }\end{array}$ & $\begin{array}{c}\text { PHY. } \\
\text { LUS }\end{array}$ & $\begin{array}{c}\text { LUS. } \\
\text { MEG }\end{array}$ & $\begin{array}{c}\text { SYL. } \\
\text { COM }\end{array}$ & $\begin{array}{c}\text { SYL. } \\
\text { BOR }\end{array}$ & $\begin{array}{c}\text { ACR. } \\
\text { SCI }\end{array}$ & \multirow{2}{*}{ Avg. } & \multirow{2}{*}{$S D$} & \\
\cline { 2 - 11 } & 70 & 14 & 38 & 19 & 18 & 69 & 21 & & & \\
\hline NE\% & 8.5 & 0.0 & 11.1 & 11.6 & 12.4 & 18.3 & 14.9 & 10.99 & 5.29 & \\
\hline SE\% & 26.2 & 28.6 & 1.40 & 18.3 & 21.8 & 24.4 & 24.7 & 20.77 & 8.47 & \\
\hline SW\% & 50.3 & 50.0 & 63.9 & 43.4 & 38.3 & 29.2 & 42.9 & 45.43 & 10.07 & \\
\hline NW\% & 15.0 & 21.4 & 14.5 & 26.7 & 27.5 & 28.1 & 17.5 & 21.53 & 5.53 & \\
\hline & & & & & & & & & & \multirow{2}{*}{$p=$} \\
\hline N\% & $\mathbf{2 3 . 5}$ & $\mathbf{2 1 . 5}$ & $\mathbf{2 5 . 6}$ & $\mathbf{3 8 . 3}$ & $\mathbf{3 9 . 9}$ & $\mathbf{4 6 . 4}$ & $\mathbf{3 2 . 4}$ & $\mathbf{3 2 . 5 1}$ & $\mathbf{8 . 7 1}$ & \multirow{2}{*}{$\mathbf{0 . 0 0 1}$} \\
\hline S\% & $\mathbf{7 6 . 5}$ & $\mathbf{7 8 . 6}$ & $\mathbf{6 5 . 3}$ & $\mathbf{6 1 . 7}$ & $\mathbf{6 0 . 1}$ & $\mathbf{5 3 . 6}$ & $\mathbf{6 7 . 6}$ & $\mathbf{6 6 . 2 0}$ & $\mathbf{8 . 2 7}$ & \\
\hline NE/SW & 0.17 & 0.00 & 0.17 & 0.27 & 0.32 & 0.63 & 0.35 & 0.27 & 0.18 & \multirow{2}{*}{$\mathbf{0 . 0 0 1}$} \\
\hline NW/SE & 0.57 & 0.75 & 1.40 & 1.46 & 1.26 & 1.15 & 0.71 & 1.04 & 0.33 & \\
\hline
\end{tabular}



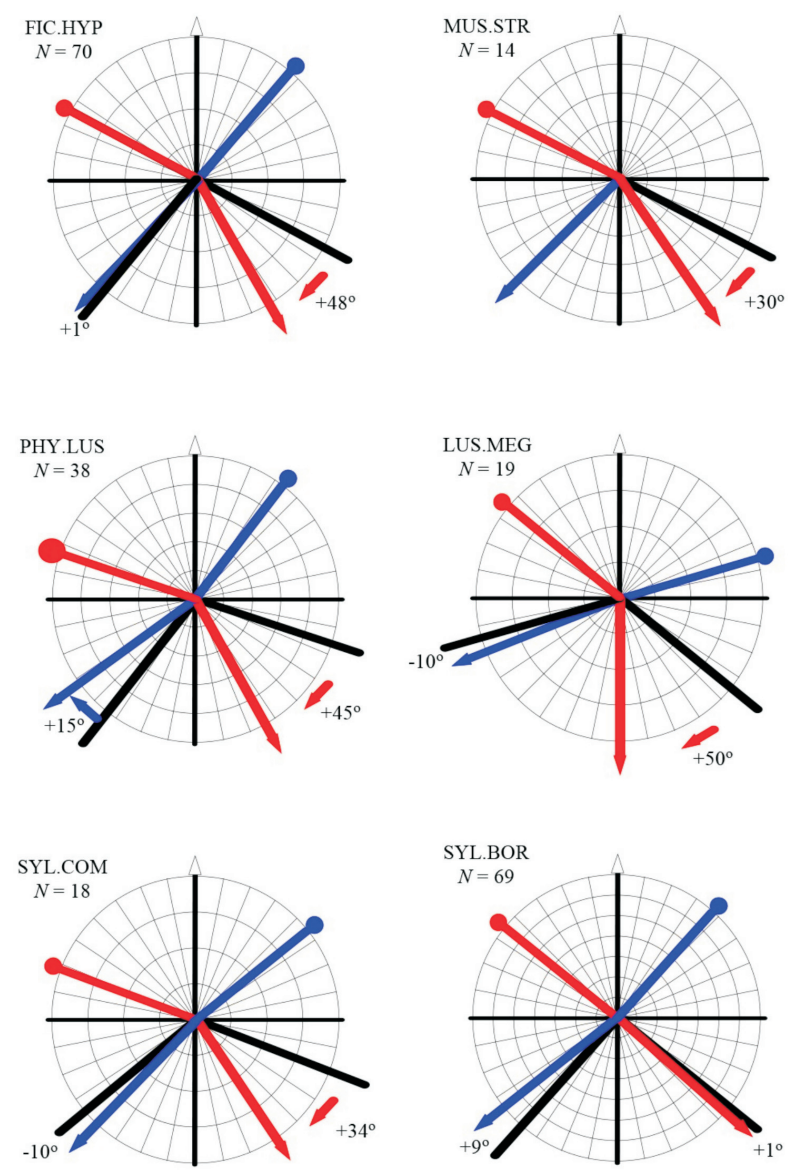

Fig. 6. Migration axes of the studied species. Dots and the lines connected to them show the arrival line of migration, and arrows indicate departure directions. Numbers represent deviation (in degrees) of departure directions from the arrival lines (+ means that the departure is shifted to the west from the arrival line)

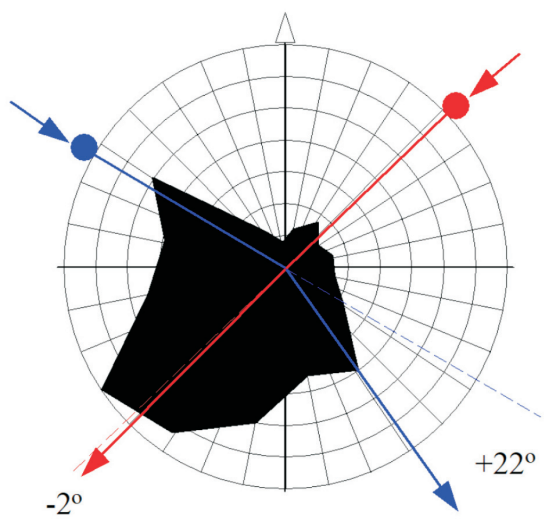

Fig. 7. Total distribution of migrants of studied species of passerines. Arrival and departure axes are shown with the average deviations of departure from the arrival line 


\section{CONCLUSIONS}

Comparison of the results of the two methodological procedures applied to the same orientation cage data indicates that they could lead to very different final pictures of the migration heading patterns, although the raw data are the same.

The differences occur due to the hidden assumptions of the older, 'classic' procedure:

- The bird in the orientation cage shows only one 'correct' direction (other headings are interpreted as 'disorientation').

- The group of individuals shows one heading to the winter-quarter (other headings are treated as the result of statistical variation from one mode of distribution or indicate 'disorientation').

The statistical tools used in the 'classic' methodology are not applicable to the actual data from the orientation cage: Batschelet's calculations and the Rayleigh test require a unimodal circular distribution, which is not the case in a high proportion of the distributions observed.

\section{ACKNOWLEDGEMENTS}

This work was only possible because of the kindness of the author of the original evaluation of these data, published years ago in The Auk - Gudrun Hilgerloh (Hilgerloh 1989b), who supplied me with the original collected data. I am very grateful for her kindness and our stimulating discussions of the methodological problems.

\section{REFERENCES}

Adamska K., Filar M. 2005. Directional preferences of the Chiffchaff (Phylloscopus collybita) and the Robin (Erithacus rubecula) on autumn migration in the Beskid Niski Mountains (S Poland). Ring 27, 2: 159-176.

Adamska K., Rosińska K. 2006. Directional preferences of the Robin (Erithacus rubecula) and the Blackcap (Sylvia atricapilla) during autumn migration at Arosio (N Italy) in 2005. Ring 28, 2: 101-111.

Akesson S., Karlsson L., Walinder G., Alerstam T. 1996. Bimodal orientation and the occurrence of temporary reverse bird migration during autumn in south Scandinavia. Behav. Ecol. Sociobiol. 38, 5: 293-302.

Batschelet E. 1981. Circular statistics in biology. Acad. Press, London

Beck W., Wiltschko W. 1981. Der Magnetkompass des Trauerschnäppers (Ficedula hypoleuca). Vogelwarte 31: 168-174.

Busse P. 1995. New technique of a field study of directional preferences of night migrants. Ring 17, 1-2: 97-116.54

Busse P. 2017. Busse's flat orientation cage vs. Emlen's funnel - compatibility, differences and conclusions. Ring 39: 3-21.

Busse P. 2018. Estimation of local heading patterns of nocturnal migrants using orientation cages. Ring 40: 31-58

Busse P., Gavrilov V. M., Ivliev V., Nowakowski J. K. 2001. Differentiation of directional preferences of some nocturnal migrants on autumn migration across the central and eastern Europe. Ring 23, 1-2: 119-130. 
Busse P., Trocińska A. 1999. Evaluation of orientation experiment data using circular statistics doubts and pitfals in assumptions. Ring 21, 2: 107-130.

Emlen S.T., Emlen J.T. 1966. A technique of recording migratory orientation of captive birds. Auk 83: $361-367$.

Formella M., Busse P. 2002. Directional preferences of the Reed Warbler (acrocephalus scirpaceus) and the Sedge Warbler (A. schoenobaenus) on autumn migration at Lake Drużno (N Poland). Ring 24, 2: 15-29.

Gwinner E., Wiltschko W. 1978. Endogenously controlled changes in migratory direction of Gardeen Warbler, Sylvia borin. J. Comp. Physiol. 125: 267-273.

Hilgerloh G. 1985a. Zugmuster von Kurz- und Weitstreckenziehern in der "Algaida" von Sanlucar de Barrameda in Südspanien. Vogelwarte 33: 69-76.

Hilgerloh G. 1985b. Zugknick im Süden der Iberischen Halbinsel? Verh. Deutschen Zool. Ges. 78: 339.

Hilgerloh G. 1988. Radar observations of passerine trans-Saharan migrants in Southern Portugal. Ardeola 35: 41-51.

Hilgerloh G. 1989a. Autumn migration of trans-Saharan migrating passerines in the Straits of Gibraltar. Auk 106: 233-239.

Hilgerloh G. 1989b. Orientation of Trans-Saharan Passerine Migrants in Southwestern Spain. Auk 106: 501-502.

Muś K. 2005. Bayesian evolution of circular data from bird orientation experiments. Presentation at Cambridge meeting.

Muś K. 2008. Bayesian analysis of the multimodal bird behaviour in orientation cage tests. ISEC-2008 Conference. DOI: 1013140/RG.2.1.4386.8323

Newton I. 2008. The Migration Ecology of Birds. Academic Press. Amsterdam.

Nowakowski J. K., Malecka A. 1999. Test of Busse's method of studying directional preferences of migrating small Passeriformes. Acta Orn. 34: 37-44.

Ożarowska A., Ilieva M., Zehtindjiev P. , Akesson S., Muś K. 2013. A new approach to evaluate multimodal orientation behaviour of migratory passerine birds recorded in circular orientation cages. Journal of Experimental Biology 216: 4038-4046. DOI: 10.11242/jeb 088757

Ożarowska A., Muś K. 2008. Orientation cage tests (2): Application in bird migration studies - paper. Conf. 6 JD Int. Conf. On Animal Navigation, Royal Institute of Navigation, University of Reading, UK. Volume 2008. DOI: 10.13140/RG.2.1.2034.9928

Ożarowska A., Yosef R. 2004. A comparison of the Emlen funnel and Busse's flat cage for orientation studies. Ring 26, 1: 59-69.

Ożarowska A., Yosef R. and Busse P. 2004. Orientation of Chiffchaff (Phylloscopus collybita), Blackcap (Sylvia atricapilla) and Lesser Whitethroat (S. curruca) on spring migration at Eilat, Israel. Avian Ecol. Behav. 12, 2004: 1-10.

Pyle P. 2002. Bird Station Manual. Review. Auk 119, 1: 290-291.

Rosińska K., Adamska K. 2007. Biometrics variation and directional preferences of immature Robins (Erithacus rubecula) caught in northern Italy during autumn migration in 2005. Ring 29, 1-2: 107-120.

Stępniewska K., El-Hallah A., Busse P. 2011. Migration dynamics and directional preferences of passerine migrants in Azraq (E Jordan) in spring 2008. Ring 33, 1-2: 3-25.

Stępniewski K., White M.L.J., Megalli M. 2011. Autumn migration of passerines in Bahariya Oasis in Egypt - where do they come from and where do they go? Ring 33, 1-2: 27-36.

Ściborska M., Busse P. 2004. Intraseasonal changes in directional preferences of Robins (Erithacus rubecula) caught on autumn migration at Bukowo-Kopań ringing station (N Poland). Ring 26, 1: 41-58.

Trocińska A., Leivits A., Nitecki C., Shydlovsky I. 2001. Field studies of directional preferences of the Reed Warbler (Acrocephalus scirpaceus) and the Sedge Warbler (A. schoenobaenus) on autumn migration along the eastern and southern coast of the Baltic Sea and in western part of Ukraine. Ring 23, 1-2: 109-117 
Zehtindjiev P., Ilieva M., Ożarowska A., Busse P. 2003. Directional behaviour of the Sedge Warbler (Acrocephalus schoenobaenus) studied in two types of orientation cages during autumn migration - a case study. Ring 25, 1-2: 53-63.

Zink G. 1977. Richtungsänderung auf dem Zuge bei europäischen Singvögeln. Vogelwarte 29: 44-54. 